\title{
Preoperative serum CA125 is an independent predictor for prognosis in operable patients with non-small cell lung cancer
}

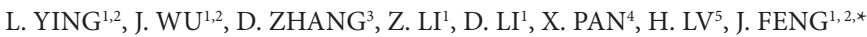 \\ ${ }^{1}$ Cancer Research Institute, Zhejiang Cancer Hospital, Hangzhou, Zhejiang, China; ${ }^{2}$ Key Laboratory Diagnosis and Treatment Technology \\ on Thoracic Oncology of Zhejiang Province, Zhejiang, China; ${ }^{3}$ College of Pharmaceutical Science, Zhejiang Chinese Medical University, \\ Hangzhou, Zhejiang, China; ${ }^{4}$ Tissue Bank, Zhejiang Cancer Hospital, Hangzhou, Zhejiang, China; ${ }^{5}$ National Clinical Research Base of \\ Traditional Chinese Medicine, Zhejiang Hospital of Traditional Chinese Medicine, Zhejiang Chinese Medical University, Hangzhou, Zhe- \\ jiang, China
}

${ }^{*}$ Correspondence: fengjg@zjcc.org.cn.

Received September 11, 2014 / Accepted January 4, 2015

\begin{abstract}
The role of serum CA125 and CEA in the prognosis of non-small cell lung cancer (NSCLC) remains controversial, especially in early stage patients, which need further clarification. Thus, in this study we carried out a large scale retrospective analysis of the prognostic value of CA125 and CEA in 645 patients with NSCLC, to explore their predictive value in the NSCLC. Patients who underwent curative surgical resection for NSCLC were from Zhejiang Cancer Hospital of China from 2006 to 2011. Microparticle enzyme immunoassay was used to measure preoperative serum CA125 and CEA. Univariate analyses and a multivariable proportional hazard Cox regression model were applied to assess the prognostic significance of the different covariates. Kaplan-Meier method was used to analyze survival curve. Both CA125 and CEA were correlated with stage, but also CA125 was different by grade, and CEA was related to histology. The Kaplan-Meier survival analysis showed that patients with elevated CA125 or CEA had unfavorable disease progression-free and overall survival time compared to those with normal CA125 or CEA. Furthermore, multivariate Cox analysis revealed that elevated CA125 had significantly higher risk for relapse (HR, 1.76; $\mathrm{p}=0.001)$ and death $(\mathrm{HR}, 1.80 ; \mathrm{p}<0.001)$, but not for elevated CEA as relapse (HR, 1.06; $\mathrm{p}=0.736)$ and death $(\mathrm{HR}, 1.25 ; \mathrm{p}=0.119)$ both were statistically non significant. This study showed that both CA125 and CEA play important roles in disease progression while only CA125 as an independent predictive marker for prognosis in patients with NSCLC.
\end{abstract}

Key words: CA125, CEA, non-small cell lung cancer, prognosis

Lung cancer, in terms of both incidence and mortality, is the most common malignant neoplasm in the world [1]. Nonsmall cell lung cancer (NSCLC) accounts for approximately $80-85 \%$ of all lung cancer cases. Despite the improvements in the diagnosis and treatment in recent years, the 5-year survival rates of lung cancer remain as low as $16 \%$, with significant variation depending on the stage of disease at the time of diagnosis [2]. The majority of people diagnosed with NSCLC are at a late stage and therefore not suitable for surgery [3]. The prognosis of advanced NSCLC patients is variable and may depend on different prognostic factors, including biological features of cancer cells. Therefore, the identification and analysis of these prognostic factors may define a subgroup of NSCLC patients with a more effective treatment.
Screening for early NSCLC biomarkers, recognition of therapeutic predictors, and development of new drugs are the key players in improving the patients' outcome $[4,5]$. The current tumor markers for NSCLC include carcinoembryonic antigen (CEA), soluble fragment of cytokeratin 19 (CYFRA21-1), tissue polypeptide antigen (TPA), neuron-specific enolase (NSE), carbohydrate antigen 125 (CA125), squamous cell carcinoma antigen (SCC) and some others [6-10]. Despite extensive studies so far, few are turned out to be useful in clinic. Even those used in clinic do not show enough sensitivity, specificity and reproducibility for general use. Among those tumor markers, CEA has been shown to carry prognostic and predictive value of risk of recurrence and of death in NSCLC independently of treatment or study design [11]. However, controversy still 
exists. A recent review [11] evaluated 18 studies in NSCLC suggested that CEA was a prognostic marker, while 7 studies had different opinions. Such discrepancy may be due to the variation of cutoff values for the CEA and different traditions and techniques in different geographic areas. In addition, an elevated CEA level can be found in a variety of cancers including colon cancers which indicates that such protein marker lack their lung-cancer specificity and may be a general cancer marker only[12,13]. CEA is also detected in other pathological conditions such as heart failure, hepatic cirrhosis and pancreatitis, which further complicate the interpretation of such markers when cancer patients simultaneously carry those diseases [14-16].

CA125 was initially described as a good prognostic indicator for lung cancer in 1990s $[17,18]$. CA125 has also been described as an important tumor marker for diagnosis and follow-up of ovarian cancer $[19,20]$. Salgia et al have evaluated 216 newly diagnosed NSCLC patients by monitoring the CA125 and CEA levels pre- and post-therapy. They concluded that CA125 and CEA were useful indicators of disease extent and therapeutic marker [21]. A significant correlation between high levels of baseline CA125 and worse survival in advanced stages (III-IV) NSCLC patients have been reported [22]. However, the role of serum CA125 in the prognosis of early stage of NSCLC remains unclear.

Therefore, in the current study, we designed a retrospective clinical study to investigate the role of CA125 and CEA in clinical characteristics and prognosis of early stage of NSCLC using a total of 645 operable NSCLC patients.

\section{Patients and methods}

Patients. A total of 645 patients with primary NSCLC that have undergone curatively resected surgery were enrolled in this retrospective study. The patients were diagnosed at the Thoracic Department of the Zhejiang Cancer Hospital in Hangzhou, China, from November 2006 to January 2011. This study was approved by the institutional review board of the hospital. All patients provided informed consent before surgery.

The baseline staging work-up included physical examination, complete blood count $(\mathrm{CBC})$, chest computed tomography $(\mathrm{CT})$, brain magnetic resonance imaging (MRI) and abdominal ultrasound. The tumor stage was defined according to the seventh edition of tumor-node-metastasis (TNM) classification. The histological diagnosis was based on the classification criteria for lung tumors of the World Health Organization and International Association for the Study of Lung Cancer (WHO/IASLC).

All patients were received standardized follow-up at a 3-month interval for the first 2 years after operation, a 6-month interval in the third year and yearly thereafter. The follow-up was conducted from 1 to 71 months, with a median period of 41 months. Disease-free survival (DFS) was defined from the date of definitive surgery to the date of local or distant progression, death or the date of last follow-up. Overall survival (OS) was calculated as the time from pulmonary surgery to death or censoring. At the time of analysis, 253 patients of the total 645 patients $(39.2 \%)$ reported relapse after surgery, and 269 patients (41.7\%) reported died. A complete work up including physical examination, $\mathrm{CBC}$, chest $\mathrm{CT}$, brain MRI and abdominal ultrasound was performed every time during the follow-up.

Measurement of serum CA125 and CEA. Preoperative serum tumor marker and clinical pathological factors were collected from the medical record database. Basically, microparticle enzyme immunoassay (ARCHITECT, Abbott, USA) was used to measure the level of preoperative serum CA125 and CEA. Serum concentrations of $35 \mathrm{U} / \mathrm{ml}$ or $5 \mathrm{ng} / \mathrm{ml}$ were used as cut-off values for CA125 and CEA respectively in the study according to standard clinical practice [23-25]. The patients having CA125 in serum above $35 \mathrm{U} / \mathrm{ml}$ or CEA in serum above $5 \mathrm{ng} / \mathrm{ml}$ were considered as elevated CA125 or CEA.

Statistical analysis. Data on the groups were compared by using the Pearson's chi-square test in univariate analysis, as well as using Fisher's exact test for histology data analysis. Survival curves were obtained by using the Kaplan-Meier method. The survival curves were compared by using the log-rank test, and statistical calculations were performed by using SPSS 13 (Chicago, IL, USA). A multivariable proportional hazard Cox regression model was applied to assess the role of different covariates including CA125 and CEA on DFS and OS. P $<0.05$ was considered as statistically significant.

\section{Results}

Clinicopathological characteristics of NSCLC patients. A total of 645 NSCLC patients were enrolled in the present study. The patients' characteristics are summarized in Table 1. The patients in this study were of a median age of 60 years (range: $30-82$ years), and comprised of 480 males (74.4\%) and 165 females (25.6\%). According to the criteria of the WHO/ IASLC classification of lung tumors, 316 (49.0\% of total) were squamous cell carcinoma, 317 (49.1\%) were adenocarcinoma and $12(1.9 \%)$ were other types of lung cancer. Three hundred and eight patients $(47.8 \%)$ were well or moderately differentiated and $280(43.4 \%)$ were poorly differentiated. In terms of the new IASLC staging system, 261 cases (40.5\%) were categorized as stage I, $166(25.7 \%)$ as stage II and $211(32.7 \%)$ as stage III. Among all patients, 195 patients (30.2\%) never smoked, while $424(65.7 \%)$ are smokers, and no records of smoking history of the remaining 26 patients (4.0\%).

Correlation of CA125 and CEA with clinicopathological characteristics. The correlation between the level of CA125 and clinicopathological characteristics before surgery was shown in Table 1. Of the total 645 patients, $124(19.2 \%)$ had elevated CA125 levels, which were related to unfavorable grade and clinical stage. The proportion of patients with elevated CA125 in poorly differentiated patients was significantly 
Table 1. Association between CA125 and clinicopathological parameters of patients with non-small cell lung cancer (NSCLC)

\begin{tabular}{|c|c|c|c|c|}
\hline \multirow[t]{2}{*}{ Variable } & \multirow{2}{*}{$\begin{array}{l}\text { Case, } \\
\mathrm{N}(\%)\end{array}$} & \multicolumn{2}{|c|}{ CA125 } & \multirow[t]{2}{*}{$P$-value ${ }^{1}$} \\
\hline & & $\begin{array}{c}\text { Normal }(\leq 35 \mathrm{U} / \mathrm{ml}) \\
(\mathrm{n}=521) \\
(\%)\end{array}$ & $\begin{array}{c}\operatorname{High}(>35 \mathrm{U} / \mathrm{ml}) \quad(\mathrm{n}=124) \\
(\%)\end{array}$ & \\
\hline Age & & & & 0.266 \\
\hline$<65$ years & $463(71.8)$ & 379 (81.9) & $84(18.1)$ & \\
\hline$\geq 65$ years & $182(28.2)$ & $142(78.0)$ & $40(22.0)$ & \\
\hline Sex & & & & 0.280 \\
\hline Male & $480(74.4)$ & $383(79.8)$ & $97(20.2)$ & \\
\hline Female & $165(25.6)$ & $138(83.6)$ & $27(16.4)$ & \\
\hline Grade of differentiation & & & & 0.015 \\
\hline Good & $308(47.8)$ & $259(84.1)$ & 49 (15.9) & \\
\hline Poor & $280(43.4)$ & $213(76.1)$ & $67(23.9)$ & \\
\hline missing & $57(8.8)$ & & & \\
\hline Histology & & & & 0.967 \\
\hline Squamous carcinoma & $316(49.0)$ & $256(81.0)$ & $60(19.0)$ & \\
\hline Adenocarcinoma & $317(49.1)$ & $255(80.4)$ & $62(19.6)$ & \\
\hline Others & $12(1.9)$ & $10(83.3)$ & $2(16.7)$ & \\
\hline Stage & & & & $<0.001$ \\
\hline I & $261(40.5)$ & $231(88.5)$ & $30(11.5)$ & \\
\hline II & $166(25.7)$ & $137(82.5)$ & $29(17.5)$ & \\
\hline III & $211(32.7)$ & $149(70.6)$ & $62(29.4)$ & \\
\hline missing & $7(1.1)$ & & & \\
\hline Smoking & & & & 0.219 \\
\hline None smoker & $195(30.2)$ & $164(84.1)$ & $31(15.9)$ & \\
\hline Smoker & $424(65.7)$ & $339(80.0)$ & $85(20.0)$ & \\
\hline missing & $26(4.0)$ & & & \\
\hline
\end{tabular}

higher than in those well or moderately differentiated patients (23.90\% versus $15.90 \%, p=0.015)$; and also, elevated CA125 was correlated with advanced stages (III) which is higher than in early stages (II or I) $(29.40 \%$ versus $17.50 \%$ versus $11.50 \%$, $p<0.001)$. However, the level of CA125 is unrelated with age, sex, histology and smoking.

Then, the correlation between CEA and clinicopathological parameters was analyzed and shown in Table 2. One hundred and seventy-eight NSCLC patients had elevated CEA (178/645, $27.6 \%)$, which was closely correlated with advanced clinical stage and histology. Among patients with stage III, 34.1\% patients had elevated CA125, compared to $26.5 \%$ in stage II and $23.0 \%$ in stage I $(p=0.025)$; similarly, the proportion of elevated CA125 in patients with adenocarcinoma was higher than that in squamous carcinoma ( $35.0 \%$ versus $21.2 \%, p<0.001$ ). However, the level of CA125 is unrelated with age, sex, grade and smoking.

Association of CA125 and CEA with disease-free survival and overall survival. The correlation of CA125 level with prognosis was analyzed by the Kaplan-Meier method. As shown in Figure 1, CA125 level showed significant correlation with both disease-free survival (DFS) $(\mathrm{p}<0.001)$ and overall survival (OS) $(\mathrm{p}<0.001)$ in NSCLC patients. Patients with elevated CA125 showed significantly reduced survival time compared with that of those with normal CA125 level, indicating that CA125 is an effective prognosis predictor for NSCLC patients. The median time of DFS or OS in patients with higher CA125 was significantly shorter than in patients with normal CA125, respectively (DFS: 26 months versus not reachable; OS: 29 months versus 61 months). This result indicated CA125 as an unfavorable factor for NSCLC patient outcomes.

The correlation of CEA level with prognosis was also analyzed by the Kaplan-Meier method. Similarly, CEA level was also showed significant correlation with both diseasefree survival (DFS) $(p=0.024)$ and overall survival (OS) $(\mathrm{p}=0.001)$ in NSCLC patients. Patients with elevated CEA showed significantly reduced survival time compared with those with normal CEA level. The median of DFS and OS in patients with higher CEA were significantly shorter than in patients with normal CEA (DFS: 45 months versus not reachable; OS: 44 months versus 61 months). This result also indicated that CEA as an unfavorable prognostic maker for NSCLC patients. 
Table 2. Association between CEA and clinicopathlogical parameters of patients with non-small cell lung cancer (NSCLC)

\begin{tabular}{|c|c|c|c|c|}
\hline \multirow[t]{2}{*}{ Variable } & \multirow{2}{*}{$\begin{array}{l}\text { Case, } \\
\mathrm{n}(\%)\end{array}$} & \multicolumn{2}{|c|}{ CEA } & \multirow[t]{2}{*}{$P$-value ${ }^{1}$} \\
\hline & & $\begin{array}{c}\operatorname{Normal}(\leq 5 \mathrm{ng} / \mathrm{ml}) \\
(\mathrm{n}=467) \\
(\%)\end{array}$ & $\begin{array}{l}\text { High }(>5 \mathrm{ng} / \mathrm{ml}) \\
(\mathrm{n}=178) \\
(\%)\end{array}$ & \\
\hline Age & & & & 0.056 \\
\hline$<65$ years & $463(71.8)$ & $345(74.5)$ & $118(25.5)$ & \\
\hline$\geq 65$ years & $182(28.2)$ & $122(67.0)$ & $60(33.0)$ & \\
\hline Sex & & & & 0.270 \\
\hline Male & $480(74.4)$ & $353(73.5)$ & $127(26.5)$ & \\
\hline Female & $165(25.6)$ & $114(69.1)$ & $51(30.9)$ & \\
\hline Grade of differentiation & & & & 0.120 \\
\hline Good & $308(47.8)$ & $228(74.0)$ & $80(26.0)$ & \\
\hline Poor & $280(43.4)$ & $191(68.2)$ & $89(31.8)$ & \\
\hline missing & $57(8.8)$ & & & \\
\hline Histology & & & & $<0.001$ \\
\hline Squamous carcinoma & $316(49.0)$ & $249(78.8)$ & $67(21.2)$ & \\
\hline Adenocarcinoma & $317(49.1)$ & $206(65.0)$ & $111(35.0)$ & \\
\hline Others & $12(1.9)$ & $12(100)$ & $0(0)$ & \\
\hline Stage & & & & 0.025 \\
\hline I & $261(40.5)$ & $201(77.0)$ & $60(23.0)$ & \\
\hline II & $166(25.7)$ & $122(73.5)$ & $44(26.5)$ & \\
\hline III & $211(32.7)$ & $139(65.9)$ & $72(34.1)$ & \\
\hline missing & $7(1.1)$ & & & \\
\hline Smoking & & & & 0.630 \\
\hline None smoker & $195(30.2)$ & $143(73.3)$ & $52(26.7)$ & \\
\hline Smoker & $424(65.7)$ & $303(71.5)$ & $121(28.5)$ & \\
\hline missing & $26(4.1)$ & & & \\
\hline
\end{tabular}

Using a multivariable Cox regression model, high serum CA125 value was shown to be an independent factor associated with significantly unfavorable DFS and OS (Table 3). These results were adjusted by patients' age, sex, grade, histology, stage and smoking status. Patients who had abnormal CA125 had an elevated risk of disease progression (Hazard ratio: 1.76) (95\% confidence interval [CI], 1.27-2.43) and a higher risk of death (Hazard ratio: 1.80) (95\% CI, 1.34-2.42) compared to the patients who had normal CA125 serum. Both risks were statistically significant $(p=0.001$ and $p<0.001)$. While no statistical significances were observed in the CEA elevated patients in both DFS and OS ( $p=0.736$ and $p=0.119$ ). These results demonstrated CA125 as an independent prognosis factor for NSCLC, but not CEA.

Table 3. Evaluation of the serum CA125 with patient survival

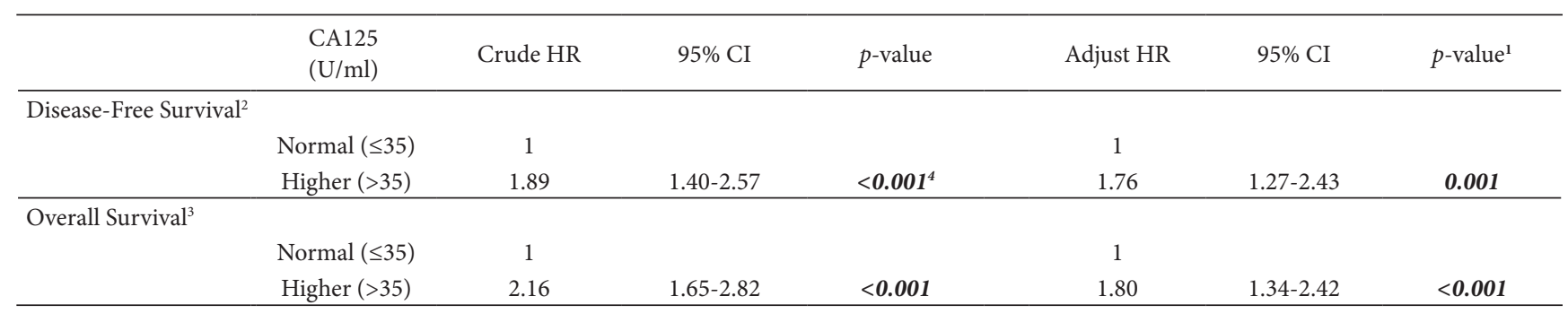

${ }^{1}$ Associations determined by multivariable Cox proportional hazards regression and adjusted for age, sex, smoking status, stage, grade and histotype; ${ }^{2} \mathrm{Hazard}$ ratio (HR) for relapse with respect to normal CA125 concentration; ${ }^{3}$ Hazard ratio (HR) for death with respect to normal CA125 concentration. ${ }^{4}$ Bold-italic values are statistically significant $(\mathrm{p}<0.05)$. 
A

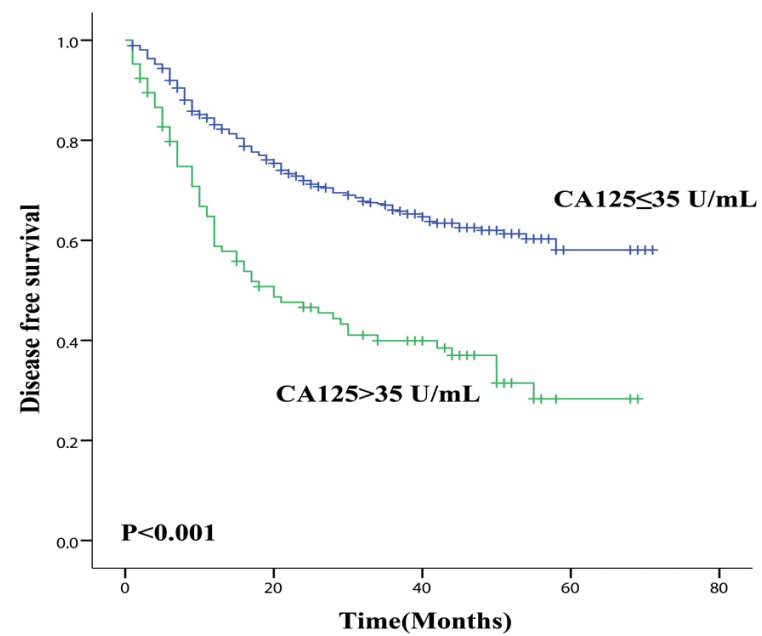

B

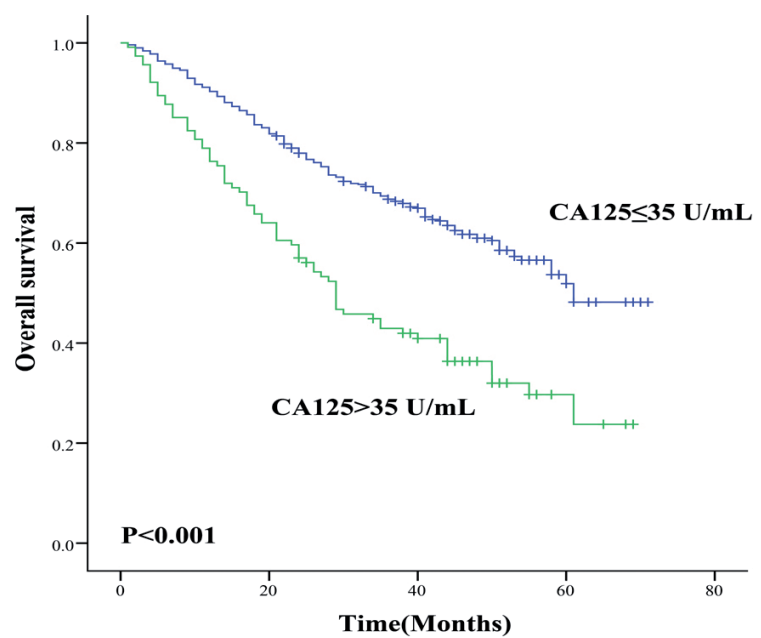

Figure 1. Association of CA125 with the prognosis of NSCLC. Data was analyzed by Kaplan-Meier method; A) disease-free survival curves; B)overall survival curves. Patients with elevated CA125 showed worse disease-free survival and overall survival.

A

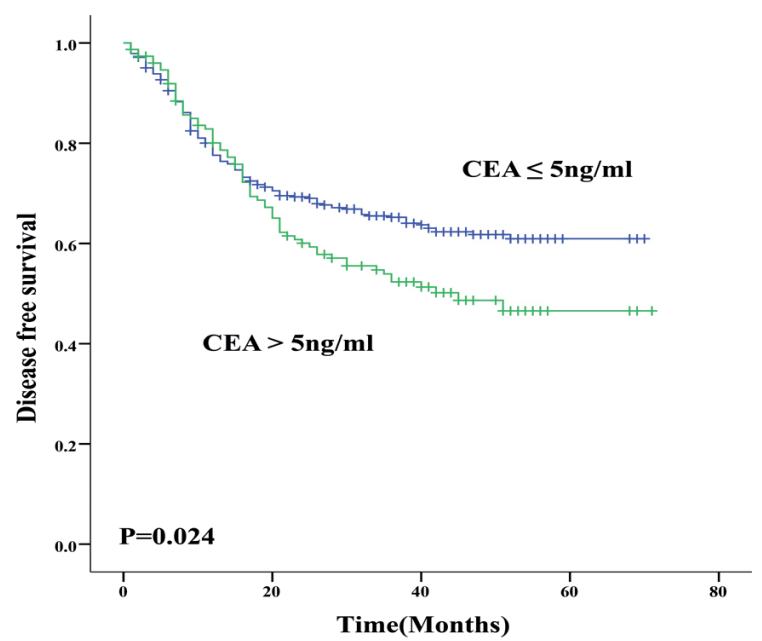

B

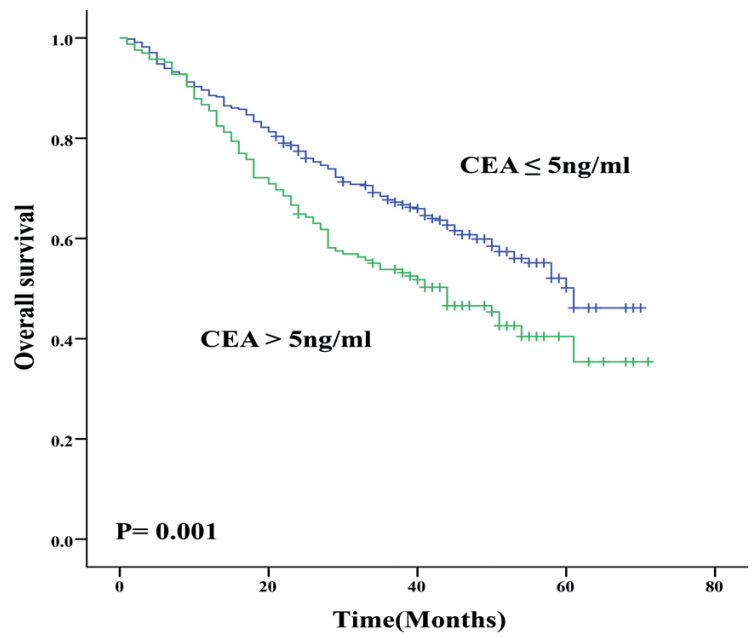

Figure 2. Association of CEA with the prognosis of NSCLC. Data was analyzed by Kaplan-Meier method; A) disease-free survival curves; B) overall survival curves. Patients with elevated CEA showed worse disease-free survival and overall survival.

Table 4. Evaluation of the serum CEA with patient survival

\begin{tabular}{|c|c|c|c|c|c|c|c|}
\hline & $\begin{array}{c}\text { CEA } \\
(\mathrm{ng} / \mathrm{ml})\end{array}$ & Crude HR & $95 \% \mathrm{CI}$ & $p$-value & Adjust $\mathrm{HR}^{1}$ & $95 \% \mathrm{CI}$ & $p$-value ${ }^{1}$ \\
\hline \multicolumn{8}{|l|}{ 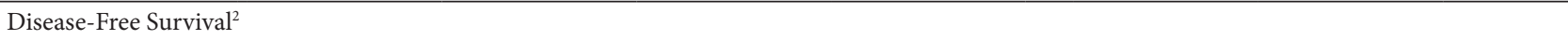 } \\
\hline & Normal $(\leq 5)$ & 1 & & & 1 & & \\
\hline & Higher $(>5)$ & 1.38 & $1.04-1.83$ & $0.024^{4}$ & 1.06 & $0.77-1.44$ & 0.736 \\
\hline \multicolumn{8}{|l|}{ Overall Survival $^{3}$} \\
\hline & Normal $(\leq 5)$ & 1 & & & 1 & & \\
\hline & Higher $(>5)$ & 1.53 & $1.19-1.97$ & 0.001 & 1.25 & $0.94-1.66$ & 0.119 \\
\hline
\end{tabular}

${ }^{1}$ Associations determined by multivariable Cox models were adjusted by age, sex, grade, histology, stage and smoking status; ${ }^{2}$ Hazard ratio (HR) for relapse with respect to normal CEA concentration; ${ }^{3} \mathrm{Hazard}$ ratio (HR) for death with respect to normal CEA concentration; ${ }^{4}$ bold-italic values are statistically significant $(p<0.05)$. 


\section{Discussion}

In this study, the role of CA125 and CEA in prognosis of the operable NSCLC patients was investigated. Both CA125 and CEA had a negative correlation with NSCLC patient outcomes. Patients with elevated expression of CA125 or CEA had a significantly worse DFS and OS. However, when multifactors were adjusted, only CA125 but not CEA had significant effect on DFS and OS, suggesting CA125 could be used as an independent biomarker to predict the prognosis of NSCLC.

Although CA125 has poor specificity as a biomarker for the diagnosis of early ovarian cancer, it correlates well with response to initial therapy for the majority of epithelial ovarian cancer $[19,20,26]$. Studies have shown that ovarian cancer patients with persistently high CA125 levels are likely to suffer from recurrence of symptoms and disease in less than 6 months and have a high likelihood of dying from disease [27]. However, the prognostic role of CA125 in NSCLC was still controversial. Many studies supported the concept that the serum CA125 levels could be associated with the tumor-node-metastasis stage, histological type, and survival rate of NSCLC [28-31]. In our study, CA125 had close correlation with differentiation of the tumor and clinical stages. Patients with poor differentiated tumor or metastatic disease (stage III) tumors had a significant higher level of CA125 as compared to the patients with good differentiated tumor or early stage of the disease, which was also been observed by other investigators [21]. Tumor differentiation and stages of diseases are critical measurements to predict the prognosis of lung cancer. This correlation may contribute to the fact that CA125 was a valuable tool to monitor the tumor recurrence and dissemination [30].

In our study, elevated serum CA125 level was associated with worse patient outcomes. Moreover, multivariate analysis by the Cox proportional hazards model revealed that preoperative serum CA125 was an independent prognostic factor in operable NSCLC patients. Patients with high CA125 had 1.76 folds risk of disease progression and 1.80 folds the risk of death of those with normal CA125 levels. Our findings are consistent with some of previous studies which were based on relatively small numbers of samples [32,33]. However, there were some controversial data regarding the elevated CA125. It has been reported that increased CA 125 was associated also with a variety of benign and malignant pathologies. Patients with greater than $35 \mathrm{U} / \mathrm{ml}$ of CA125 may have cardiovascular and chronic liver disease or previous surgical procedures (abdominal, thoracic, and neurological) $[34,35]$. The elevation CA125 associated with surgery is temporary and will regress to baseline spontaneously [36]. Therefore, it is important to monitor the level of CA125 pre-operation and post-operation to make sure this prognostic factor is appropriately interpreted. Our study suggested that CA125 could be an independent prognosis factor for early stage NSCLC, although CA 125 may not as a specific biomarker, while it is very useful when combined with other detection methods.
Some studies have shown that the levels of CEA but not CA125 were significantly higher among patients with adenocarcinomas [21]. Our study showed the same results. But the role of CEA as a prognostic marker in NSCLC patients is still not clear. Grunnet et al reviewed 25 publications which investigated the role of CEA as a prognostic marker in NSCLC and found that in 18 of these studies, CEA was found to be a useful prognostic marker for either OS recurrence after surgery or/ and progression free survival while 7 of the studies were not reliable [11]. According to multivariate Cox regression in our study, CEA is not an independent factor in determining the prognosis of the NSCLC patients. Our result suggested that CEA may provide prognostic information, but unlike CA125, CEA by itself may not be a sufficiently strong indicator to guide treatment decisions. There are some limitations in our study. We did not perform consecutive measurement of the CA125 during the follow-up or for recurrence assessment. And this is a retrospective study based on patients from one hospital and selection bias may not be completely avoided.

In conclusion, our study demonstrated preoperative serum CA125 and CEA are closely correlated with unfavorable DFS and OS, and intriguingly preoperative serum CA125 could be as an independent predictor for recurrence and death in operable patients with NSCLC, and it would be very useful when combined with other detection methods.

Acknowledgements: The study was supported by the Ministry of Public Health Science Research Foudation-Zhejiang Province Medical Science Major Technology Fund Project (No.WKJ 201484951), Zhejiang Province Natural Science Foundation (LY13H160028) and Zhejiang Province Medicine and Health Foundation (2013KYA028 and 2015KYA035).

\section{References}

[1] JEMAL A, SIEGEL R, XU J, WARD E Cancer statistics, 2010. CA Cancer J Clin 2010; 60: 277-300. http://dx.doi. $\underline{\operatorname{org} / 10.3322 / \text { caac. } 20073}$

[2] MAIONE P, ROSSI A, SACCO PC, BARESCHINO MA, SCHETTINO C. et al. Advances in chemotherapy in advanced non-small-cell lung cancer. Expert Opin Pharmacother 2010; 11:2997-3007. http://dx.doi.org/10.1517/14656566.2010.511 $\underline{615}$

[3] GOVINDAN R, BOGART J, VOKES EE Locally advanced non-small cell lung cancer: the past, present, and future. J Thorac Oncol 2008; 3: 917-28. http://dx.doi.org/10.1097/ ITO.0b013e $318180270 \mathrm{~b}$

[4] POSTMUS PE Screening for lung cancer, an ongoing debate. Ann Oncol 2008; 19 Suppl 7: vii25-7. http://dx.doi. org/10.1093/annonc/mdn464

[5] KONOPA K Do we have markers to select patients for adjuvant therapies of non-small-cell lung cancer? Ann Oncol 2010; 21 Suppl 7: vii199-202. http://dx.doi.org/10.1093/ annonc/mdq452

[6] MOLINA R, FILELLA X, AUGE JM, FUENTES R, BOVER I. et al. Tumor markers (CEA, CA 125, CYFRA 21-1, SCC and 
NSE) in patients with non-small cell lung cancer as an aid in histological diagnosis and prognosis. Comparison with the main clinical and pathological prognostic factors. Tumour Biol 2003; 24: 209-18. http://dx.doi.org/10.1159/000074432

[7] MOLL R., FRANKE WW, SCHILLER DL, GEIGER B, KREPLER R The catalog of human cytokeratins: patterns of expression in normal epithelia, tumors and cultured cells. Cell 1982; 31: 11-24. http://dx.doi.org/10.1016/0092-8674(82) $90400-7$

[8] GIOVANELLA L, CERIANI L, BANDERA M, BEGHE B, RONCARI G Evaluation of the serum markers CEA, NSE, TPS and CYFRA 21.1 in lung cancer. Int J Biol Markers 1995; 10: $156-60$.

[9] MARGOLIS M L, HYZY JB, SCHENKEN LL, SCHEPART BS Serum tumor markers in non-small cell lung cancer. A comparative analysis. Cancer 1994; 73: 605-9. http:// dx.doi.org/10.1002/1097-0142(19940201)73:3<605::AIDCNCR2820730317>3.0.CO;2-T

[10] BARAK V, GOIKE H, PANARETAKIS KW, EINARSSON $\mathrm{R}$ Clinical utility of cytokeratins as tumor markers. Clin Biochem 2004; 37: 529-40. http://dx.doi.org/10.1016/j. clinbiochem.2004.05.009

[11] GRUNNET M, SORENSEN JB Carcinoembryonic antigen (CEA) as tumor marker in lung cancer. Lung Cancer 2012; 76: 138-143. http://dx.doi.org/10.1016/j.lungcan.2011.11.012

[12] FORONES NM, TANAKA M CEA and CA 19-9 as prognostic indexes in colorectal cancer. Hepatogastroenterology 1999; 46: 905-8.

[13] HAMPTON R, WALKER M, MARSHALL J, JUHL H Differential expression of carcinoembryonic antigen (CEA) splice variants in whole blood of colon cancer patients and healthy volunteers: implication for the detection of circulating colon cancer cells. Oncogene 2002; 21: 7817-23. http://dx.doi. org/10.1038/sj.onc.1205906

[14] VIZZARDI E, D'AlOIA A, CURNIS A, DEI CAS L Carbohydrate antigen 125: a new biomarker in heart failure. Cardiol Rev 2013; 21: 23-6. http://dx.doi.org/10.1097/ CRD.0b013e318265f58f

[15] DIBAISE JK, DONOVAN JP Markedly elevated CA125 in hepatic cirrhosis: two case illustrations and review of the literature. J Clin Gastroenterol 1999; 28: 159-61. http://dx.doi. org/10.1097/00004836-199903000-00016

[16] MACDONALD F, DOWNING R, ALLUM WH Expression of CA125 in pancreatic carcinoma and chronic pancreatitis. Br J Cancer 1988; 58: 505-6. http://dx.doi.org/10.1038/ bjc. 1988.251

[17] KIMURA Y, FUJII T, HAMAMOTO K, MIYAGAWA N, KATAOKA M. et al. Serum Ca125 Level Is a Good Prognostic Indicator in Lung-Cancer. British Journal of Cancer 1990; 62: 676-678. http://dx.doi.org/10.1038/bjc.1990.355

[18] DIEZ M, TORRES A, MAESTRO ML, ORTEGA MD, GOMEZ A. et al. Prediction of survival and recurrence by serum and cytosolic levels of CEA, CA125 and SCC antigens in resectable non-small-cell lung cancer. Br J Cancer 1996; 73: 1248-54. http://dx.doi.org/10.1038/bjc.1996.239

[19] BAST RC, JR. BADGWELL D, LU Z, MARQUEZ R, ROSEN D. et al. New tumor markers: CA125 and beyond. Int J
Gynecol Cancer 2005; 15 Suppl 3: 274-81. http://dx.doi. org/10.1111/j.1525-1438.2005.00441.x

[20] NAGELE F, PETRU E, MEDL M, KAINZ C, GRAF AH. et al. Preoperative CA 125: an independent prognostic factor in patients with stage I epithelial ovarian cancer. Obstet Gynecol 1995; 86: 259-64. http://dx.doi.org/10.1016/00297844(95)00126-C

[21] SALGIA R, HARPOLE D, HERNDON 2ND JE, PISICK E, ELIAS A. et al. Role of serum tumor markers CA 125 and CEA in non-small cell lung cancer. Anticancer Res 2001; 21: 1241-6.

[22] CEDRES S, NUNEZ I, LONGO M, MARTINEZ P, CHECA E. et al. Serum tumor markers CEA, CYFRA21-1, and CA-125 are associated with worse prognosis in advanced non-smallcell lung cancer (NSCLC). Clin Lung Cancer 2011; 12: 172-9. http://dx.doi.org/10.1016/j.cllc.2011.03.019

[23] COLEMAN RL, RAMIREZ PT, GERSHENSON DM Neoplastic diseases of the ovary: screening, benign and malignant epithelial and germ cell neoplasms, sex-cord stromal tumors. In: Lentz GM, Lobo RA, Gershenson DM, Katz VL, eds. Comprehensive Gynecology. 6th ed. Philadelphia, Pa: Elsevier Mosby; 2012: 731-771.

[24] National Comprehensive Cancer Network. NCCN Clinical Practice Guidelines in Oncology: Ovarian cancer: including fallopian tube cancer and primary peritoneal cancer. Version 2.2013 .

[25] LOCKER GY, HAMILTON S, HARRIS J, JESSUP JM, KEMENY N. et al. ASCO 2006 update of recommendations for the use of tumor markers in gastrointestinal cancer. J Clin Oncol. 2006;24:5313-5327. http://dx.doi.org/10.1200/ LCO.2006.08.2644

[26] HAWKINS RE, ROBERTS K, WILTSHAW E, MUNDY J, MCCREADY VR The clinical correlates of serum CA125 in 169 patients with epithelial ovarian carcinoma. Br J Cancer 1989; 60: 634-7. http://dx.doi.org/10.1038/bjc.1989.329

[27] KRIVAK TC, TIAN C, ROSE GS, ARMSTRONG DK, MAXWELL GL A Gynecologic Oncology Group Study of serum CA-125 levels in patients with stage III optimally debulked ovarian cancer treated with intraperitoneal compared to intravenous chemotherapy: an analysis of patients enrolled in GOG 172. Gynecol Oncol 2009; 115: 81-5. http://dx.doi. org/10.1016/j.ygyno.2009.06.021

[28] GASPAR MJ, DIEZ M, RODRIGUEZ A, RATIA T, MARTIN DUCE A. et al. Clinical value of CEA and CA125 regarding relapse and metastasis in resectable non-small cell lung cancer. Anticancer Res 2003; 23: 3427-32.

[29] HATZAKIS KD, FROUDARAKIS ME, BOUROS D, TZANAKIS N, KARKAVITSAS N. et al. Prognostic value of serum tumor markers in patients with lung cancer. Respiration 2002; 69: 25-9. http://dx.doi.org/10.1159/000049366

[30] DIEZ M, GOMEZ A, HERNANDO F, ORTEGA MD, MAESTRO ML. et al. Serum CEA, CA125, and SCC antigens and tumor recurrence in resectable non-small cell lung cancer. Int J Biol Markers 1995; 10: 5-10.

[31] BRUNDAGE MD, DAVIES D, MACKILLOP WJ Prognostic factors in non-small cell lung cancer: a decade of progress. Chest 2002; 122: 1037-57. http://dx.doi.org/10.1378/ chest.122.3.1037 
[32] DIEZ M, TORRES A, POLLAN M, GOMEZ A, ORTEGA D. et al. Prognostic significance of serum CA 125 antigen assay in patients with non-small cell lung cancer. Cancer 1994; 73: 1368-76. http://dx.doi.org/10.1002/1097-0142(19940301)73:5<1368::AID-CNCR2820730510>3.0.CO;2-O

[33] YU D, DU K, LIU T, CHEN G Prognostic Value of Tumor Markers, NSE, CA125 and SCC, in Operable NSCLC Patients. Int J Mol Sci 2013; 14: 11145-56. http://dx.doi.org/10.3390/ ijms 140611145

[34] MIRALLES C, OREA M, ESPANA P, PROVENCIO M, SANCHEZ A. et al. Cancer antigen 125 associated with multiple benign and malignant pathologies. Ann Surg Oncol 2003; 10: 150-4. http://dx.doi.org/10.1245/ ASO.2003.05.015

[35] EPINEY M, BERTOSSA C, WEIL A, CAMPANA A, BISCHOF P CA125 production by the peritoneum: in-vitro and in-vivo studies. Hum Reprod 2000; 15: 1261-5. http:// dx.doi.org/10.1093/humrep/15.6.1261

[36] NUNEZ GR, ITO C, DEL GIGLIO A Increased serum CA125 levels in patients with lung cancer post thoracotomy. South Med J 2009; 102: 427-8. http://dx.doi.org/10.1097/ SMJ.0b013e31819b9a8f 